\title{
Is Nurses' Creativity An Advantage or Disadvantage? A Qualitative Study in an Iranian Context
}

\author{
Sara Shahsavari Isfahani ${ }^{1}$; Mohammad Ali Hosseini ${ }^{1, *}$; Masood Fallahi Khoshknab ${ }^{1}$; Hamid \\ Peyrovi $^{2}$; Hamid Reza Khanke ${ }^{1}$ \\ ${ }^{1}$ Department of Nursing, University of Social Welfare and Rehabilitation Sciences, Tehran, IR Iran \\ ${ }^{2}$ Department of Critical Care Nursing, School of Nursing and Midwifery, Iran University of Medical Sciences, Tehran, IR Iran \\ ${ }^{*}$ Corresponding Author: Mohammad Ali Hosseini, Department of Nursing, University of Social Welfare and Rehabilitation Sciences, Tehran, IR Iran. Tel: +98-2122180132, Fax: +98- \\ 2122180132, E-mail: mahmaimy2020@gmail.com
}

Received: June 2, 2014; Revised: July 7, 2014; Accepted: August 13, 2014

\begin{abstract}
Background: Recently, global nursing experts have been aggressively encouraging nurses to pursue creativity and innovation in nursing to improve nursing outcomes. Nurses' creativity plays a significant role in health and well-being. In most health systems across the world, nurses provide up to $80 \%$ of the primary health care; therefore, they are critically positioned to provide creative solutions for current and future global health challenges.

Objectives: The purpose of this study was to explore Iranian nurses' perceptions and experiences toward the expression of creativity in clinical settings and the outcomes of their creativity for health care organizations.

Patients and Methods: A qualitative approach using content analysis was adopted. Data were collected through in-depth semistructured interviews with 14 nurses who were involved in the creative process in educational hospitals affiliated to Jahrom and Tehran Universities of Medical Sciences in Iran.

Results: Four themes emerged from the data analysis, including a) Improvement in quality of patient care, b) Improvement in nurses' quality of work, personal and social life, c) Promotion of organization, and d) Unpleasant outcomes.

Conclusions: The findings indicated that nurses' creativity in health care organizations can lead to major changes of nursing practice, improvement of care and organizational performance. Therefore, policymakers, nurse educators, nursing and hospital managers should provide a nurturing environment that is conducive to creative thinking, giving the nurses opportunity for flexibility, creativity, support for change, and risk taking.
\end{abstract}

Keywords:Qualitative Content Analysis; Nurses; Creativity; Innovation; Outcomes; Iran

\section{Background}

Recently, global nursing experts have been aggressively encouraging nurses to pursue creativity and innovation in nursing in order to improve nursing outcomes $(1,2)$. The world of healthcare is changing (3).Today's health care organizations need creative and innovative solutions. Creativity and innovation are not new concepts to the nursing profession. Nurses worldwide are engaged in innovative activities on a daily basis; activities motivated by the need to improve care outcomes and reduce costs to the health system (4). Failure to acknowledge and encourage creativity in nurses may hinder future development and innovations in nursing practice and in nursing science (5). Nurses often encounters unexpected situations and involves taking care of patients with different backgrounds and health conditions; hence, they need to go beyond nursing routine and acquire creative thinking to make useful decisions (6). In most health systems, nurses are the main professional component of 'front line' staff providing up to $80 \%$ of primary health care. As such, they are critically positioned to provide the creative and innovative solutions for current and future global health challenges (4).

Moreover, being effective, health care organizations must facilitate creative responses to increasingly complex health problems. These organizations and their staff must innovate and make change as health care needs and demands shift. Meeting these challenges requires the complete use of entire available human and mental resources (4). Among the most important of these resources is creativity, which is the capacity to think of old problems in new ways to change the perspectives, or to create novel and useful approaches to construct our organizations' work better and to meet the needs of patients (7).

Creativity is a major issue in nursing profession and the most important characteristic of nurses and in the health care, it is a complex issue (8). The term creativity and innovation are often used interchangeably; however, there is a clear distinction between them, creativity is the 
generation of novel and useful ideas, while innovation is the implementation of the ideas (9).

Recent nursing literature has repeatedly proclaimed the need for creativity in nursing (10). Studies have shown that creativity is not highly rewarded in practice; however, it is supposed to be in the theory (11) and although creativity has been featured in the nursing literature for many years, it has been the subject of only a small amount of research in nursing. Therefore, an edified understanding of creativity and its dynamics and place in nursing has never been attained (12). Also, the most studies on creativity have been conducted in nursing education (13), but creativity in the clinical settings and its outcomes for patients, nurses and health care organizations have not been extensively studied and its consequences is still not clear. Hence, the area of creativity within the medicine and nursing appears underdeveloped and the outcomes of creativity in these fields are unknown (14). In addition, most researches about the nursing creativity in Iran have been conducted with quantitative approach (15-17). Therefore, considering the existing evidence in Iran and lack of comprehensive study on the nurses' creativity, this study explores the perception and experiences of creative nurses about outcomes of their creativity in clinical settings in the cultural context of Iran.

\section{Objectives}

Considering the importance of creativity in nursing and the role of nurses in health care organizations, this study aimed to determine the Iranian nurses' perceptions and experiences of creativity in clinical settings and the outcomes of their creativity for health care organizations.

\section{Patients and Methods}

A qualitative approach using content analysis was adopted for this study to facilitate a rich description of the understanding and experiences of creative clinical nurses about outcomes or consequences of creativity in health care settings in an Iranian context.

\subsection{Data Collection}

Data were collected through a semistructured interview. It was composed of two open-ended questions (interview guide) as follows: Have had any experience regarding creativity in your workplace? And, what were the outcomes of creativity for you, patients, and hospitals? Also, some probing questions were asked for additional clarification to answers given by the participants. No prejudices or personal opinions were involved in the interview process, and semistructured guidelines were adopted to guide interviewees to express their experiences as far as possible. Interviews lasted between 30 - 90 minutes and were performed in a quiet place in participants' working units. After recording the interviews, they were transcribed verbatim immediately and analyzed. All interviews were performed by one female interviewer and were audio- taped with the nurses' consent. The interviewer received formal qualitative curriculum training and had clinical practicum teaching experience of 21 years, which would help the participant enter the interview situation and build a trustworthy relationship. The data collection, data analysis and participants' selection was continued until data saturation occurred and a rich description of nurses' experiences was obtained. The data collection was interrupted after 14 interviews, because it was clear that no new concepts had emerged after 13 interviews.

\subsection{Setting and Participants}

In this study, 14 nurses (5 females and 9 males) who had worked in different units of educational hospitals affiliated to Jahrom and Tehran Medical Universities, Iran, were recruited by purposeful sampling with the maximum variation sampling to achieve variation in nurse's gender and work experiences as well as educational levels (Table 1). Two nurses refused to participate in the study after initial agreement (both because of problems in setting time for interview). This study was conducted from June 2012 to December 2013. Inclusion criteria, including the nurses who had offered novel and useful ideas, products, services or procedures in clinical settings and had willingness to participate in the study. In this study, matrons, supervisors, and head nurses were asked to nominate nurses who provided creativity and innovation at workplace.

\begin{tabular}{|cc}
\hline \multicolumn{1}{|c}{ Table 1. Participants' Characteristics of the Study ${ }^{\mathrm{a}}$} \\
\hline Age Distribution, $\mathbf{y}$ & No. $(\%)$ \\
\hline $25-34$ & $7(50)$ \\
$35-44$ & $4(28.6)$ \\
$45-54$ & $2(14.3)$ \\
\hline $55-64$ & $1(7.14)$ \\
\hline Gender & \\
\hline Male & $9(64.3)$ \\
\hline Female & $5(35.7)$ \\
\hline Educational Level & \\
\hline MSN & $3(21.4)$ \\
\hline BSN & $8(57.14)$ \\
\hline AND & $1(7.14)$ \\
\hline LPN & $2(14.28)$ \\
\hline Work experience, $y$ & \\
\hline $5-9$ & $2(14.28)$ \\
\hline $10-14$ & $6(42.86)$ \\
\hline $15-19$ & $3(21.43)$ \\
\hline $20-24$ & $1(7.14)$ \\
\hline $25-29$ & $1(7.14)$ \\
\hline $30-34$ & $1(7.14)$ \\
\hline Total & 14 \\
\hline
\end{tabular}

a Abbreviations: MSN, master of science in nursing; BSN, bachelor of science in nursing; AND, associate degree in nursing; LPN, licensed practical nurse. 


\subsection{Ethical Considerations}

The Ethical and Research Committee of University of Social Welfare and Rehabilitation Sciences in Tehran approved this study (2ID11767). Before starting each interview, all participants were informed about the objectives and method of the study. They were also informed that participation in the study is voluntary; therefore, they could refuse to participate or withdraw from the study at any time. Moreover, the participants were reassured that their responses would be kept confidential and their identities would not be revealed in research reports and publications of the study. Finally, the participants who agreed to participate in the study were asked to sign a written consent.

\subsection{Data Analysis}

Data were analyzed using a conventional content analysis approach. To analyze the data, 'Framework' as a method of qualitative data analysis was used. 'Framework' is an analytical process, which involves a number of distinct though highly interconnected stages (18). It has five key stages. In the first stage or familiarization stage, we transcribed the data verbatim and read each interview several times to gain a sense of content. The second stage or identifying a thematic framework, involved dividing the text into meaning units. The condensed meaning units were abstracted and labeled with a code, which constitute the manifest content. In the third stage or indexing, we compared the various codes based on differences and similarities and sorted them into subcategories and categories and collated all the relevant coded into data extracts within the identified categories. In the fourth stage or charting, we read all the collated extracts for each category and considered whether they appeared to form a coherent pattern. Then, we considered the validity of individual categories in relation to the dataset and whether our candidate categories "accurately" reflected the meaning evident in the dataset as a whole. Two researchers independently examined the data for categories. In the fifth stage or mapping and interpretation, we defined and further refined the categories (18).

\subsection{Consideration of Rigor}

Similar to all qualitative approaches, content analysis entails discovering and exploring the processes in the findings (19). To ensure credibility, member checking was used in which the first author performed a member check for 9 participants through providing a summary of identified themes for clarification. Data were coded by the authors after they were compared with each another. In cases of disagreement, explanation and clarification were provided by the research team to reach the final confirmation.

\section{Results}

In total, 14 nurses (9 males and 5 females) aged $27-57$ years old participated in this study. Their work experiences were between 7 - 30 years and most of them had worked in different units of the hospital (Table 1). Data analysis resulted in identifying four main themes: a) Improvement in patients' quality of care, b) Improvement in nurses' quality of work, personal and social life, c) Promotion of organization and d) Unpleasant outcomes. The rest of the text discusses the meaning of each theme, with quotations from participants.

\subsection{Improvement in Patients' Quality of Care}

When nurses were asked their experiences about outcomes of creativity in clinical settings, they pointed to the more cooperation of patients, doing the work more convenient and achieving better therapeutic results.

A nurse with 15 years of work experience stated that: "I made little crafts such as sofas and chairs or little fishes with waste papers, and next morning when I wanted to give medication, first I gave it to the child. Therefore, I communicate with the kids in this way that it caused my work to be more convenient. For example, The child used the drug much better and was more cooperative during change dressing.

Furthermore, participants mentioned that creativity caused facilitation of patient care and the patients received better care and had higher satisfaction. For example a nurse with 7 years of work experience who had made a stretcher that equipped with a cassette for taking X-ray and especially for patients with multiple trauma stated: "There, they put the radiology cassette in the drawer under the stretcher to take an X-ray; so, there is no need to move the patient from the stretcher to the radiology bed".

One nurse with 11 years of work experience also stated: "I used odorless Whitex (a commercial disinfectant solution in Iran) in surgical wards for cleaning surfaces and this leads to high patients' satisfaction because smelling Whitex bothered them."

\subsection{Improvement in Nurses' Quality of Work, Per- sonal and Social Life}

Some participants believed that expressing creative ideas in the workplace had had positive effects on their physical and mental health and they achieved self-belief and felt happiness. Also, pleasure of discovering new creative ideas and doing a larger work had given them intrinsic satisfaction and feeling of pride.

One nurse with 14 years of work experience cited that: "This means that you're satisfied and happy of doing the right thing, it will make you happy."

Also, a nurse with 30 years of work experience mentioned that: "I thought if I want to go short, do not look for a bigger work or a larger service, I really do not enjoy, and maybe even have a negative impact on my health." A nurse with 17 years of work experience cited that: "The first thing that creativity had had for me is self-belief. I 
found a kind of confidence. For example, when the colleagues say: can you make a certain thing? I felt confidence. This was the most important thing for me."

Moreover, participants pointed out to the gaining social respect in the community and they believed that creativity in nursing causes acceptance of friends and the community, being known, being seen with a positive outlook and being a model for other nurses or students.

One nurse with 20 years of work experience stated: "when friends praise that you offered a new job, had an invention, or an innovation, maybe I am satisfied with these aspects, well it's good in the community. For example, when they say you are creative, one feels that he is difference with the other people and this is due to the feedbacks that community gives to you."

In addition, participants mentioned that creativity is the main engine for the development of health care workers and organizations. And nurses' creativity leads to innovation, entrepreneurship, and is a source of income.

A creative and entrepreneur nurse with 13 years of work experience: "If there were problems in the operating room, I designed and made them. Then, I established a company in Industrial Park and I just make some of the medical devices for production in the company and I have about 8 - 9 workers."

\subsection{Promotion of Organization}

According to the nurses who participated in the study, creativity, innovation, and entrepreneurship in nursing has led to growth and promotion of the agency and nurses have had more desire to work.

One nurse with 7 years of work experience stated: "My creativity and appliances that I had made has led the university to promote a lot. For example, the university announced that it was supposed to have 3 patent annually based on their strategic plan. My creativity had many benefits for them. Vice Chancellor of Research and Technology in the Ministry of Health wrote that this university has grown by 200 percent. Well, they were grown. Also, they had a positive view and said if we encourage someone, others are also encouraged."

Also, participants believed that creativity has led to reduction of hospital costs, building devices similar to foreign samples with better quality, using the supplies in the hospital and greater comfort of patients and coworkers (health workers).

A nurse with 14 years of work experience cited that: "I designed and built a bed special for doing percutaneous nephrolitotomy in the operating room, at that time it was about 240 million rials (or around 240,000 dollars). I designed it and put in the hospital, the entire cost for building it, was 8000,000 rials (or around 1000 dollars)."

\subsection{Unpleasant Outcomes}

In addition to positive or pleasant outcomes, nurses implied to unpleasant or negative outcomes includ- ing: lack of support by some managers and authorities including little encouragement, providing low-cost financing, paying out-of-pocket personally, disruption of family roles, hard- working, cutting out a lot of things in life, and long-time warranty of devices that were made by creative nurses.

One nurse with 25 years of work experience stated: "Well according to the current situation, I can say that what I expected, outcome is not pretty for me both from incentives, (I mean the system), and financial aspects."

And a nurse with 27 years of work experience cited that: "Do you think a creative person as a father in the home could be a positive and effective parent for the children. Can he be? Not really. Unfortunately it is not supported, the creative nurse must work very hard, and cutting out a lot of things in the life, and this is a fact."

\section{Discussion}

In the present research, nurses were asked about outcomes of their creativity in clinical settings. Findings indicated good information about the unique experiences and perspectives of creative nurses and showed that creativity has many benefits for the patients, nurses, their colleagues, as well as the hospitals and the universities. Also, it had some negative effects on nurses that sometimes led to discouragement and displeasure. However, nurses' experiences indicated that positive aspects outweighed the negative ones. Therefore, we can say that nurses' creativity for health care system is a privilege, not a disadvantage.

As the complexity of health care and nursing escalates, health care providers are challenged to think more creatively and develop innovations that advance the knowledge, learning, and service contributions of their discipline to the health care enterprise. Nursing requires creative thought and innovative action in service of the greater good (20). Examining the first theme showed that nurses' creativity causes high quality of patients care. It prevents more invasive procedures, more cooperation and satisfaction of the patients, and facilitation of patients' care. Achieving high quality in patient care is important because of the pivotal role of delivering direct care in nursing as well as the growing emphasis on improving hospitals' credibility and clinical status. In addition, patient satisfaction is considered as an indicator of quality of health care services (21). Creativity gives the nurses feeling of empowerment. Empowerment energizes the people who are closest to the patients and the technology to continuously look for ways to provide high quality patient care and to improve processes. The accumulation of ideas,both great and little by many people, will result in better patient care and practical efficiencies (22). In addition, creative modalities offer nurses a new perspective on how to care for patients. The link between creativity and healing is well-documented (23). Ultimately, fostering the ethics of change, innovation and creativ- 
ity led to the development of professional nursing practices and advanced patient care (24).

The second theme indicated that creativity causes improvements in nurse's quality of work, personal and social life. Nurses stated that creativity leads to innovation, entrepreneurship, establishment of a company, manufacturing of medical equipment's and this makes financial benefits for them. Nurses' innovation is the key to the change and transformation in health care systems (25). In Iran, creativity, innovation and entrepreneurial skills has not been considered as part of the "formal education" and socialization of nurses in the workplace. Creativity and innovation in nursing is outspread, accidental issue and is not as organized and managed, and not being seen as part of the work to be done by the health care workers, but is seen as something extra to the "real work" of nurses. Therefore, it is essential to manage creativity and innovation in nursing education and practice since it is a developing process and does not happen quickly. Also, internal climate of health care organizations must provide and support the nurses' innovation and entrepreneurship.

Nurses' experiences indicated that creativity enhanced self-esteem, self-belief and feeling of happiness. Successfully, dealing with a difficult situation increases belief in the ability to handle other similar situations. Creatively resolving a present problem boost the individuals' feeling of confidence (26). Creativity also leads to more satisfaction. When an individual faces with a worrisome problem and uses his or her ingenuity to solve it, an increased sense of satisfaction will be resulted in (26). Also, satisfaction with creativity is supported, at organizational level, by teamwork, autonomy, domain-relevant competences, and at the individual level, is enhanced by the strength of intrinsic initial motivations (27).

Nurses experienced social respect and feeling of pride and they stated that creativity had positive effect on their physical and mental health. Pride is produced when an outcome is perceived as the result of an individual's own actions, particularly if he or she receives accolades from others (26). Also, the creative process is seen as a process of discovery, which stimulates and guides expression by the creator, eliciting positive feelings and emotions, thereby promoting their health and well-being (14). In addition, the results of studies indicated that participating in creative activities can have a positive effect on behavioral changes, self-confidence, self-esteem, levels of knowledge and physical activity (28).

Creative nurses pointed out that creativity led to promotion of health care organization. Creativity and innovation are keys to the survival and growth of both health care system and nursing. The nurse gains personal satisfaction, rewards, and recognition, whereas the organization survives, thrives, and prospers (29). Therefore, creativity and innovation are key elements for improvement of the organization, and, more specifically, for nursing to find alternatives for solving the problems related to the occupation as a whole (30).
Creative nurses experienced some negative outcomes, such as disturbances in family role, high workload and time pressure that caused them being fatigue and also impediment to creativity. Creativity takes time, a great deal of hard work, and strenuous mental energy (31). Therefore, providing sufficient time is a factor for promoting creativity, time is necessary to think creatively, to explore different perspectives, and to play with ideas (32). In addition, when workload pressure goes beyond a certain threshold in the work environment, represent an impediment to creativity (27).

The nurses pointed to the lack of financial support and attention of managers, so in order to establish a promoting climate for creativity to prosper, the organization should provide a warm intellectual environment that gives employees recognition, prestige, and an opportunity to participate. Nurse managers should promote creativity through sensitivity that gives nurses the attention they want and treats them as distinct individuals (33). Consequently, creativity is crucial in all institutions where nurses are trained. The critical importance of identifying, nurturing and protecting innovators, as well as the role of managers and mentors, is emphasized.

\subsection{Limitations}

While this study was performed with only 14 nurses, it provided a good description about the phenomenon of nurses' creativity in clinical settings. The flexibility and other strengths of the qualitative methodology made it possible to explore nurses' experiences. Results from this study can be used to establish guidelines on how to foster creativity in health care professionals, especially practical nurses and nursing students as future nurses. Moreover, as this is a qualitative study, the study group is in no way a representative sample. Hence, the results of this study are predominantly representative of the group of creative nurses who participated in this study and cannot be generalized to all nurses. However, generalizability was neither the aim nor the claim of this qualitative research study.

\section{Acknowledgements}

This study is a part of a PhD thesis supported by The Deputy of Research at The University of Social Welfare and Rehabilitation Sciences in Tehran. The authors would like to appreciate all the nurses for their cooperation and participation in this study.

\section{Funding/Support}

This article has been derived from a research project and was funded by Deputy of Research, University of Social Welfare and Rehabilitation Sciences, Tehran, Iran.

\section{Authors' Contributions}

Study concept and design: Sara Shahsavari Isfahani, 
Mohammad Ali Hosseini and Hamid Peyrovi. Acquisition of data: Sara Shahsavari Isfahani. Analysis and interpretation of data: Sara Shahsavari Isfahani, Mohammad Ali Hosseini and Hamid Peyrovi. Drafting of the manuscript, Sara Shahsavari Isfahani. Critical revision of the manuscript for important intellectual content: Masood Fallahi Khoshknab, Hamid Peyrovi and Hamid Reza Khankeh. Study supervision: Mohammad Ali Hossein, Masood Fallahi Khoshknab, Hamid Peyrovi and Hamid Reza Khankeh.

\section{References}

1. Weng RH, Huang CY, Chen LM, Chang LY. Exploring the impact of transformational leadership on nurse innovation behaviour: a cross-sectional study. J Nurs Manag. 2013.

2. Weng RH, Huang CY, Huang JA, Wang MH. The cross-level impact of patient safety climate on nursing innovation: a cross-sectional questionnaire survey. J Clin Nurs. 2012;21(15-16):2262-74.

3. Porter-O'Grady T. Innovation and creativity in a new age for health care. J NY State Nurses Assoc. 2003;34(2):4-8.

4. Hughes F. Nurses at the forefront of innovation. Int Nurs Rev. 2006;53(2):94-101.

5. Fasnacht PH. Creativity: a refinement of the concept for nursing practice. J Adv Nurs. 2003;41(2):195-202.

6. Chan ZC. A systematic review of creative thinking/creativity in nursing education. Nurse Educ Today. 2013;33(11):1382-7.

7. Denhardt RB, Denhardt JV. Aristigueta MP. Managing Human Behavior in Public and Nonprofit Organizations.California, Thousand Oaks: SAGE Publication; 2002.

8. Plsek P. Complexity and the adoption of innovation in health care.Washington, DC: National Institute for Healthcare Management Foundation and National Committee for Quality in Health Care; 2003.

9. Man J. Creating innovation. Work Study. 2001;50(6):229-34.

10. Potgieter E. The Whole Brain Creativity Model: implications for nursing education and practice. Curationis. 1999;22(4):41-8.

11. Huang LS, Sternberg PW. Genetic dissection of developmental pathways. Worm Book. 2006:1-19.

12. Hancock HA. . Discovering OPUS-Exploring creativity in midwifery and nursing. [Thesis submitted in total fulfilment for the degree of Doctor of Philosophy in the Graduate School of Education .]. : University of Adelaide; 2002.

13. Woodrow DJ. . Nursing and Creativity: Does the Speciality Make a Difference? . [A thesis submitted in partial fullfilment of the requirements of the Degree of Master of Science in nursing.]. : The University of British Columbia; 1992.

14. schmid T. Promoting health through creativity. School of Health Sciences UONA editor. London: Whurr Publishers Ltd; 2005.

15. Jafarpour M, Erfannia N, Rashid M. . Assessment the creativity of nurses in Public Hospitals in North Khorasan State. National Conference on Nursing Organizational Behavior. Islamic Azad University, Shirvan Branch, Department of Nursing, Shirvan, Iran:. 2011.

16. Moshirabadi Z, Seyedfatemi N, Borimnejad L, Haghani H, Yazdanipour M. Comparison of creativity skills between the first year and the fourth year undergraduate nursing students. Iranian J Nursing Res. 2013;8(1):49-57.

17. Jokari M, Jorfi H, Ebadi GH. Study the effect of creativity and innovation on nurses productivity in Taleghani Hospital(Case Study in Abadan of Iran). I. J. C. R. B. 2012;4(4).

18. Bryman A, Burgess RG. Analyzing Qualitative Data.New York: Taylor \& Francis e-library; 2002.

19. Mehrdad N, Oskouie F, Seyed Fatemi N, Rezaei M. Qualitative Content Analysis.Tehran: Boshra Publication; 2013.

20. Pesut DJ. Creativity and innovation: thought and action. Creat Nurs. 2013;19(3):113-21.

21. Institute of Medicine Crossing the Quality Chasm.. A New Health System for the 21st Century.Washington, DC: The National Academies Press; 2001.

22. Powell L. Conducting hospital employee satisfaction surveys.: Mountain States Group, Inc;2001.

23. Lane MR. Creativity and spirituality in nursing: implementing art in healing. Holist Nurs Pract. 2005;19(3):122-5.

24. Gilmartin MJ. Creativity: The Fuel of Innovation. Nurs Admin. Q. 1999;23(2):1-8.

25. Smith SB, Flarey DL. Reengineering nursing and health care.USA:Aspen Publishers, Inc; 1995.

26. Im S, Montoya MM, Workman JP. Antecedents and Consequences of Creativity in Product Innovation Teams. J Prod Innovat Manag. 2013;30(1):170-85.

27. Sacchetti S, Tortia EC. Satisfaction with Creativity: A Study of Organizational Characteristics and Individual Motivation.J Happiness Stud. 2013;14(6):1789-811.

28. Bungay $\mathrm{H}$, Vella-Burrows $\mathrm{T}$. The effects of participating in creative activities on the health and well-being of children and young people: a rapid review of the literature. Perspect Public Health. 2013;133(1):44-52.

29. Roussel LA, Swansburg RC. Management and leadership for nurse administrators. 5th edUSA: Jones \& Bartlett Publishers, LLC; 2009.

30. Feldman LB, Ruthes RM, Cunha IC. [Creativity and innovation: competences on nursing management]. Rev Bras Enferm. 2008;61(2):239-42.

31. Shalley CE, Gilson LL. What leaders need to know: A review of social and contextual factors that can foster or hinder creativity. Leadership Quart. 2004;15(1):33-53.

32. Amabile TM, Gryskiewicz SS. Creativity in the R\&D Laboratory:: Center for Creative Leadership; 1987.

33. Swansburg EO, Fairchild WL, Fryer BJ, Ciborowski JJ. Mouthpart deformities and community composition of Chironomidae (Diptera) larvae downstream of metal mines in New Brunswick, Canada. Environ Toxicol Chem. 2002;21(12):2675-84. 